\title{
Environmental degradation effect on the properties of Bi-2212 highly textured rods
}

J.C. Diez, G. Constantinescu, Sh. Rasekh, L.C. Estepa, M.A. Madre, A. Sotelo

ICMA (CSIC-Universidad de Zaragoza), C/Maria de Luna 3, 50018-Zaragoza (Spain)

\begin{abstract}
It is well know that $\mathrm{H}_{2} \mathrm{O}$ and $\mathrm{CO}_{2}$ (both present in the atmosphere) can react chemically with BSCCO superconductors, especially with the alkaline-earth cations, producing chemical degradation and reducing their performances. In this work, Bi-2212 highly textured rods were grown from the melt through a laser floating zone melting technique. In order to determine the influence of $\mathrm{H}_{2} \mathrm{O}$ and $\mathrm{CO}_{2}$ on these bulk textured samples, they were immersed in distilled water and in $\mathrm{CO}_{2}$ saturated water. The electrical and mechanical properties evolution of these rods was determined as a function of the immersion time in both media and compared with their initial properties. It has been found that performances degradation was higher in distilled water than in $\mathrm{CO}_{2}$ saturated one. Nevertheless, in any case, the degradation has been found to be not very important.
\end{abstract}

Keywords: Bi-2212, Bulk superconductors, Directional growth, Resistivity, Critical current, Mechanical properties.

Corresponding author: M.A. Madre. e-mail: amadre@unizar.es. Tel: +34 976762516 fax: +34 976 761957 


\section{Introduction}

The fabrication of bulk high- $T_{c}$ superconducting ceramics with well oriented microstructure and being able of carrying high currents at $77 \mathrm{~K}$, is of great interest for the development of practical devices [1]. $\mathrm{Bi}_{2} \mathrm{Sr}_{2} \mathrm{CaCu}_{2} \mathrm{O}_{8+\delta}(\mathrm{Bi}-2212)$ superconductors have demonstrated that they are suitable for many applications when they are properly processed in order to obtain a good grain alignment [2, 3]. Among other techniques which produce well textured materials [4-6], the directional grown from the melt, as the Laser Floating Zone (LFZ) method, has demonstrated to be a useful technique for rapidly growing well textured BSCCO rods [7-10]. As it was reported in previous works [11], the microstructure of these superconducting materials is characterized by a good alignment of the grains, with their $a-b$ planes quasi-parallel to the growth direction, and possessing very low porosity. The Bi-2212 bulk materials textured by this technique have very interesting electrical properties that allow developing current leads and fault current limiters [12, 13]. One of the main advantages of this method is that samples can be rapidly grown due to the large thermal gradients present at the solid-liquid interface.

On the other hand, the development of practical applications of high temperature superconductors requires not only the knowledge of their electrical properties, but also the mechanical ones. Moreover, for any practical application, it is necessary to take into account their reactivity with the environment. These processes are mainly produced with $\mathrm{H}_{2} \mathrm{O}$ and $\mathrm{CO}_{2}$ present in the atmosphere which can lead to the degradation of their electrical and mechanical properties by reacting mostly with the alcaline-earth cations. The general degradation mechanisms have been already described as follows $[14,15]$ :

$$
\begin{aligned}
& \mathrm{Bi}_{2} \mathrm{Sr}_{2} \mathrm{CaCu}_{2} \mathrm{O}_{8}+3 \mathrm{H}_{2} \mathrm{O} \rightarrow 2 \mathrm{Sr}(\mathrm{OH})_{2}+\mathrm{Ca}(\mathrm{OH})_{2}+\mathrm{CuO}+\mathrm{CuBi}_{2} \mathrm{O}_{4} \\
& \mathrm{Sr}(\mathrm{OH})_{2}+\mathrm{CO}_{2} \rightarrow \mathrm{SrCO}_{3}+\mathrm{H}_{2} \mathrm{O} \\
& \mathrm{Ca}(\mathrm{OH})_{2}+\mathrm{CO}_{2} \rightarrow \mathrm{CaCO}_{3}+\mathrm{H}_{2} \mathrm{O}
\end{aligned}
$$

In this work, the environmentally chemical stability of Bi-2212 textured rods grown by a laser floating zone technique has been studied by means of the immersion of some of the samples in distilled water while others were kept into carbon dioxide saturated one. A comparison of the 
electrical (I-V curves at $77 \mathrm{~K}$ and electrical resistivity between 77 and $300 \mathrm{~K}$ ) and mechanical (flexural strength measured by three-point bending) properties as a function of the immersion time in each media has been made. These properties have been also compared with those obtained for the original samples, used as reference. Moreover, the measured properties have been related with the internal and superficial microstructure.

\section{Experimental}

Initial $\mathrm{Bi}_{2} \mathrm{Sr}_{2} \mathrm{CaCu}_{2} \mathrm{O}_{8+\delta}$ polycrystalline ceramics have been prepared from commercial $\mathrm{Bi}_{2} \mathrm{O}_{3}$ (Panreac, >98\%), $\mathrm{SrCO}_{3}$ (Panreac, >98\%), $\mathrm{CaCO}_{3}$ (Panreac, >98.5\%) and $\mathrm{CuO}$ (Panreac, >97\%) powders by the classical solid state method. They were weighed in the adequate atomic proportions, mixed in an agate ball mill at $300 \mathrm{rpm}$ for $30 \mathrm{~min}$ in acetone media in order to obtain an homogeneous mixture. The resulting suspension was then dried in an IR evaporation system until the acetone was totally removed. The dried powder was then subjected to a two-step thermal treatment, under air $\left(12 \mathrm{~h}\right.$ at $750{ }^{\circ} \mathrm{C}$ and $12 \mathrm{~h}$ at $\left.800{ }^{\circ} \mathrm{C}\right)$, in order to decompose the metallic carbonates, which could disturb the solidification front in the texturing process. These prereacted powders were subsequently used to prepare cylindrical precursors ( 120 mm long and $~ 3 \mathrm{~mm}$ diameter) by cold isostatic pressing with an applied pressure of around 200MPa during 1 minute. The obtained cylinders were used as feed in a directional solidification process performed in a LFZ installation described elsewhere [16]. The textured bars were obtained using a continuous power Nd:YAG laser $(\lambda=1064 \mathrm{~nm})$, under air, at a growth rate of $30 \mathrm{~mm} / \mathrm{h}$ and a relative rotation of $18 \mathrm{rpm}$ between seed and feed. Using these growth conditions and adjusting the laser power output to obtain a molten zone of approximately 1-1.5 times the rod diameter, it is possible to obtain a stable growth, allowing the fabrication of geometrically homogeneous bars.

It is well-known that $\mathrm{Bi}-2212$ ceramics present an incongruent melting and, in consequence, after texturing it is necessary to perform a thermal treatment in order to produce the Bi-2212 superconducting phase from the secondary phases formed in the growth process $[9,16]$. This 
annealing process has been performed under air, and consisted in two steps: $60 \mathrm{~h}$ at $860{ }^{\circ} \mathrm{C}$ to obtain the $\mathrm{Bi}-2212$ phase, followed by $12 \mathrm{~h}$ at $800{ }^{\circ} \mathrm{C}$ to adjust the oxygen content and, finally, quenched in air to room temperature. In order to measure the electrical properties, low resistance silver contacts were painted on the samples before annealing. After the thermal treatment, these silver contacts have typical resistance values below $1 \mu \Omega$.

The chemical degradation of the samples has been made by immersing some of the annealed samples in distilled $\mathrm{H}_{2} \mathrm{O}$, others in $\mathrm{CO}_{2}$ saturated water, and, finally, the reference ones have been kept in a dry box under nitrogen atmosphere.

Critical current measurements at $77 \mathrm{~K}, I_{c}(77 \mathrm{~K})$, and electrical resistivity variation with temperature, $\rho(\mathrm{T})$, between $77 \mathrm{~K}$ and room temperature, were performed on $30 \mathrm{~mm}$ long samples using the common four-probe configuration. The current was kept fixed at $1 \mathrm{~mA}$ in the resistivity measurements, while the critical currents were determined in self-field using the standard $1 \mu \mathrm{V} / \mathrm{cm}$ criterion.

The flexural strength for the different groups of samples (10 samples for each condition) has been measured by three-point bending tests using a fixture of $10 \mathrm{~mm}$ loading spam in a mechanical testing machine (Instron 5565). The tests were performed under air on the original samples, used as control, and in previously immersed ones for 24 days in the different media. A drop of water (distilled or $\mathrm{CO}_{2}$ saturated water), added with a syringe, covered the central section of the rods during mechanical tests to ensure that the fracture region was immersed in the reaction media during the whole process. The flexural strength was computed from the maximum load achieved in the test, according to the strength of materials theory for an elastic beam of circular section. In order to find the relative effect of each environment, a dynamic fatigue experiment was performed. For this reason the flexural tests were done under different cross-head speeds $(1,10$ and $100 \mu \mathrm{m} / \mathrm{min})$ for each environmental condition. 
Microstructural characterization has been performed on the rods surface as well as on polished cross-sections of the samples, using a scanning electron microscope (FESEM Carl Zeiss MERLIN"M) equipped with an energy dispersive spectroscopy, EDX system (INCA 350 Oxford).

\section{Results and discussion}

In Fig. 1, it is displayed the representative longitudinal microstructure observed in samples after the annealing process. In this figure it can be clearly seen that $\mathrm{Bi}-2212$ is the major phase (grey contrast, \#1), accompanied of several minor amounts of Bi-2201 (light grey contrast, \#2) and secondary phases (black contrast, \#3) which have been identified as Bi-free Sr-Ca-Cu oxides. These Sr-Ca-Cu oxides are mainly located at the outside edge of the rods, where radial temperature gradients disturb the directional growth.

In Fig. 2 it is displayed the microstructural evolution for samples immersed in distilled water for 24 hours and 24 days. From these micrographs, it is clear that after 24 hours (see Fig. 2a) samples are nearly unchanged. On the other hand, a thin layer of reaction products can be observed on the 24 days surface sample (see Fig. 2b, grey layer \#1). Moreover, the formation of these reaction compounds has been produced by the migration of alkaline earth cations (Ca and Sr) from regions close to the sample surface, leading to the production of a new phase with $\mathrm{Bi}$ - and $\mathrm{Cu}$-rich composition (see Fig 2b, white contrast \#2), that have been associated to $\mathrm{CuBi}_{2} \mathrm{O}_{4}$ by EDX. All these microstructural surface modifications are confirmed when observing the samples surfaces. In Fig. 3, the surfaces of the immersed samples in distilled water for 24 hours (Fig. 3a) and 24 days (Fig. 3b) are displayed. The differences, which can be observed between both micrographs, seem to be not very important, taken into account the different reaction time for each sample. In any case, some reaction products can be observed in both samples surfaces with small spot shapes. In order to identify the degradation products produced in these surfaces, higher magnification micrographs have been performed and displayed in Fig 4. In this figure it is clear that several regions with two main different morphologies can be found in the samples surface. One of these 
regions show flower-like shapes (see Fig. 4b) and the other with globular and column-like ones (see Fig. 4c). These efflorescence have been identified, by means of EDX measurements, as Sr- and Carich regions (for the flower-like shape grains) and Cu-rich regions (globular and column-like shape grains). These results are in agreement with previously reported reaction products found in BSCCO ceramics [15]. In order to confirm the chemical nature of these degradation products water $\mathrm{pH}$ measurements have been performed before and after 24 days samples immersion. The obtained values indicated an increase on the $\mathrm{OH}^{-}$concentration which is a consequence of the following reaction:

$$
\mathrm{H}_{2} \mathrm{O}+\underline{\mathrm{O}}^{2-} \rightarrow \mathrm{OH}^{-}+\underline{\mathrm{OH}}^{-}
$$

where the underlined members of the equation indicate the ions of the crystalline network, in agreement with previously reported data [17].

In the case of samples immersed in $\mathrm{CO}_{2}$ saturated water, the situation is very similar but $\mathrm{CO}_{2}$ seems to produce a higher amount of reaction products, as it is illustrated in Fig.5. In this figure a representative superficial SEM micrograph of a sample immersed for 24 days in $\mathrm{CO}_{2}$ saturated water, is displayed. The big agglomerates which can be observed in the micrograph correspond to Cu-rich regions, in contrast with the observations performed in samples immersed in distilled water, where the biggest reaction products were associated to Sr- and Ca-rich regions. This difference can be related to the increased solubility of $\mathrm{Ca}$ and $\mathrm{Sr}$ carbonates in $\mathrm{CO}_{2}$-rich media. Moreover, this $\mathrm{CO}_{2}$ also avoids the formation the $\mathrm{Cu}$-rich columnar-grain shapes.

From the mechanical point of view, the degradation produced by each media must be evaluated in order to determine the samples evolution with time. In Fig. 6 it is displayed the mean strength values for three point bending tests performed under different cross-head speeds and degradation media. As it can be clearly seen mean values are always slightly higher for the reference samples, confirming the environmental damage produced by water and $\mathrm{CO}_{2}$ saturated water. Moreover, this damage is slightly reduced when $\mathrm{CO}_{2}$ saturated water is used, compared with pure distilled water. In any case, mean strength values decrease when cross-head speed is reduced due to a subcritical 
crack growth process. The stable growth of cracks under applied stresses lower than that for fast fracture (slow crack growth, SCG) is usually studied by means of a power-law function [18]:

$$
v=\frac{d a}{d t}=A K_{I}^{n}
$$

where $v$ is the crack growth velocity, $K_{I}$ is the stress intensity factor at the tip of a crack with length $a$, and $A$ and $n$ are parameters depending on the material and environment. The $n$ values have been computed from the slope of the $\log \left(\sigma_{f}\right)$ versus $\log (d \varepsilon / d t)$, where $\varepsilon$ is the strain, obtaining values of 51 and 46 for distilled water and $\mathrm{CO}_{2}$ saturated water, respectively. These values confirm the previously discussed microstructural observations which showed that samples immersed in $\mathrm{CO}_{2}$ saturated water produced a higher amount of reaction products, compared with samples immersed in distilled water (see Figs. 3 and 5).

The very similar internal microstructure and phase content observed previously, together with the presence of most of the reaction products in the samples surface, is reflected in the electrical properties. The resistivity vs. temperature measurements between 77 and $300 \mathrm{~K}$ showed that all the samples possess similar behaviour and $T_{\mathrm{C}}$ values around $88 \mathrm{~K}$ in all cases. This is a clear confirmation that degradation reactions are mostly produced in the samples surfaces, with no apparent influence on the electrical conducting paths along the samples. The evolution found on the resistivity values is also maintained on the $J_{\mathrm{c}}$ measurements at $77 \mathrm{~K}$ represented in Fig. 7. In this figure it is clear that all samples have, using the $1 \mu \mathrm{V} / \mathrm{cm}$ criteria, approximately, the same $J_{c}$ values, around $2000 \mathrm{~A} / \mathrm{cm}^{2}$, confirming the assessments about the $T_{c}$ evolution.

All the obtained data show that LFZ textured materials possess a very high degradation resistance due to their high density, which avoids the internal degradation by liquid and/or gas infiltration through the porosity.

\section{Conclusions}


Bi-2212 superconducting textured rods have been successfully fabricated through a LFZ method.

The environmental susceptibility of these rods has been studied by means of three-point bending tests in air, in distilled water, and in $\mathrm{CO}_{2}$ saturated water, at room temperature. The obtained mechanical and electrical results have been nearly constant, independently of the degradation media and time. These results clearly indicate that degradation processes are only produced in the samples surface, due to the absence of porosity in the samples which avoids their internal degradation by the environment infiltration.

\section{Acknowledgements}

The authors wish to thank the Gobierno de Aragón (Research Groups T12 and T87), the Spanish Ministry of Science and Innovation-FEDER (Project MAT2008-00429), MINECO-FEDER (Project MAT2011-22719), and the Universidad de Zaragoza-Ibercaja (Project UZ2011-TEC-03) for financial support. The technical contributions of J. A. Gómez and C. Gallego are also acknowledged. Sh. Rasekh acknowledges a JAE-PreDoc grant from the CSIC.

\section{References}

1. M. Chen, L. Donel, M. Lakner, and W. Paul, J. Eur. Ceram. Soc. 24, 1815 (2004)

2. P. F. Hermann, Handbook of Applied Superconductivity (IOP Publishing, Bristol, 1998).

3. M. Noe, K. P. Juengst, F. N. Werfel, S. Elschner, J. Bock, F. Breuer, and R. Kreutz, IEEE Trans. Appl. Supercond. 13, 1976 (2003).

4. V. Garnier, R. Caillard, A. Sotelo, and G. Desgardin, Physica C 319, 197 (1999).

5. H. Maeda, K. Ohya, M. Sato, W. P. Chen, K. Watanabe, M. Motokawa, A. Matsumoto, H. Kumakura, and J. Schwartz, Physica C 382, 33 (2002).

6. M. S. Martin-Gonzalez, J. Garcia-Jaca, E. Moran, and M. A. Alario-Franco, J. Mater. Res. 14, 3497 (1999).

7. R. S. Feigelson, D. Gazit, D. K. Fork, and T. H. Geballe, Science 240, 1642 (1988). 
8. A. Sotelo, M. Mora, M. A. Madre, J.C. Diez, L. A. Angurel, and G. F. De la Fuente, J. Eur. Ceram. Soc. 25, 2947 (2005).

9. M. Mora, A. Sotelo, H. Amaveda, M. A. Madre, J. C. Diez, F. Capel, and J. M. López-Cepero, J. Eur. Ceram. Soc. 27, 3959 (2007)

10. M.F. Carrasco, R.A. Silva, R.F. Silva, et al. Physica C 460, 1347 (2007)

11. M. Mora, E. Martinez, J.C. Diez, L.A. Angurel, and G.F. de la Fuente, J. Mater. Res. 15, 614 (2000)

12. L. Garcia-Tabarés et al, IEEE Trans. Appl. Supercond. 11, 2543 (2001)

13. L.A. Angurel, J.C. Diez, G.F. de la Fuente, et al., Phys. Status Solidi A-Appl. Mat. 203, 2931 (2006)

14. S.G. Jin, Z.Z. Zhu, L. Liu, and Y.L. Huang, Solid State Commun. 74, 1087 (1990)

15. D. Lee, R.A. Condrate Sr., and J.A. Taylor, Physica C 350, 1 (2001)

16. L.A. Angurel, J.C. Diez, E. Martinez, J.I. Peña, G.F. de la Fuente, and R. Navarro, Physica C 302, 39 (1998)

17. E. Russ, J. Estienne, G. Vacquier, and A. Casalot, Mat. Res. Bull. 31, 751 (1996)

18. D. Munz, and T. Fett, Ceramics: Mechanical Properties, Failure Behaviour, Materials Selection, Springer 2001. 


\section{Figure captions:}

Figure 1. Representative microstructure (longitudinal view) observed in samples after annealing process. Although $\mathrm{Bi}-2212$ is the major phase (grey contrast, \#1) some minor amounts of Bi-2201 (light grey contrast, \#2) and Bi-free Sr-Ca-Cu oxides (black contrast, \#3) have been identified.

Figure 2. Representative microstructure (transversal views) for samples immersed in distilled water for 24 hours (a) and 24 days (b). A thin layer of reaction products can be observed on the 24 days surface sample (grey layer \#1). As a result of the degradation a new phase, identified as $\mathrm{CuBi}_{2} \mathrm{O}_{4}$ by EDX, has been produced (white contrast \#2).

Figure 3. Surfaces of the immersed samples in distilled water for 24 hours (a) and 24 days (b). Some reaction products can be observed in both samples surfaces with small spot shapes.

Figure 4. Higher magnification surface of the sample immersed 24 days in distilled water (a).The reaction products adopt two different morphologies (enlarged views). One of these regions show flower-like shapes (b) and the other with globular and column-like ones (c). These efflorescence have been identified, by means of EDX measurements, as Sr- and Ca-rich regions (for the flowerlike shape grains) and Cu-rich regions (globular and column-like shape grains).

Figure 5. Surfaces of the immersed samples in $\mathrm{CO}_{2}$ saturated water for 24 hours (a) and 24 days (b). It is possible to see a higher amount of reaction products when compared with samples immersed in distilled water. The agglomerates have been identified, by means of EDX measurements, as $\mathrm{Cu}$-rich regions.

Figure 6. Mean strength values and standard deviation obtained in three point bending tests at different cross-head speeds. Reference, $\mathbf{\square}$ water inmersed, and $\diamond \mathrm{CO}_{2}$ saturated water inmersed samples.

Figure 7. J vs. E measurements at $77 \mathrm{~K}$ for $\bigcirc$ Reference, water inmersed for $\boldsymbol{\square} 24 \mathrm{~h}$ and $\boldsymbol{\Lambda} 24$ days, and $\mathrm{CO}_{2}$ saturated water inmersed for $\diamond 24 \mathrm{~h}$ and $\triangleleft 24$ days samples. 
Figure 1

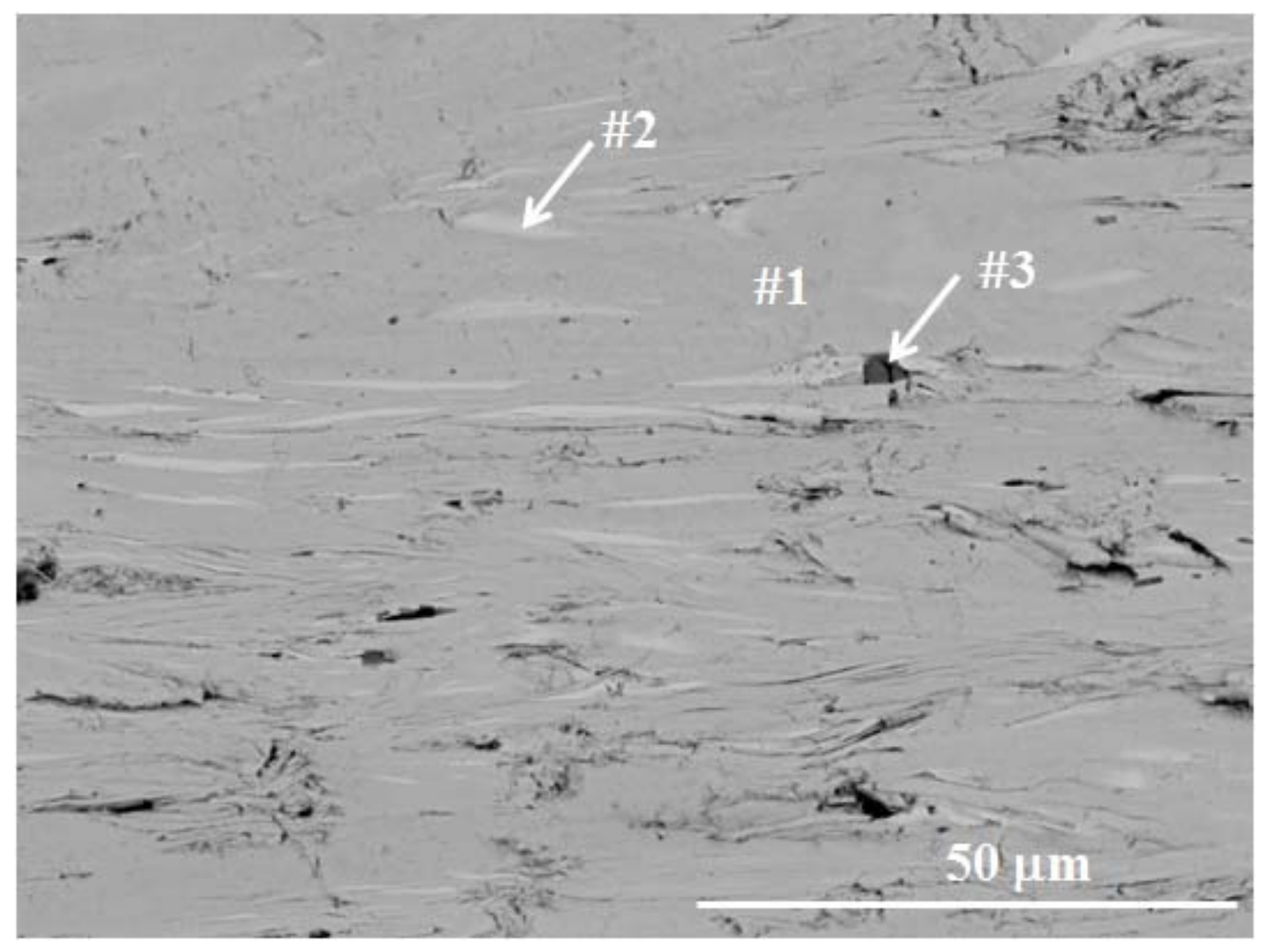


Figure 2
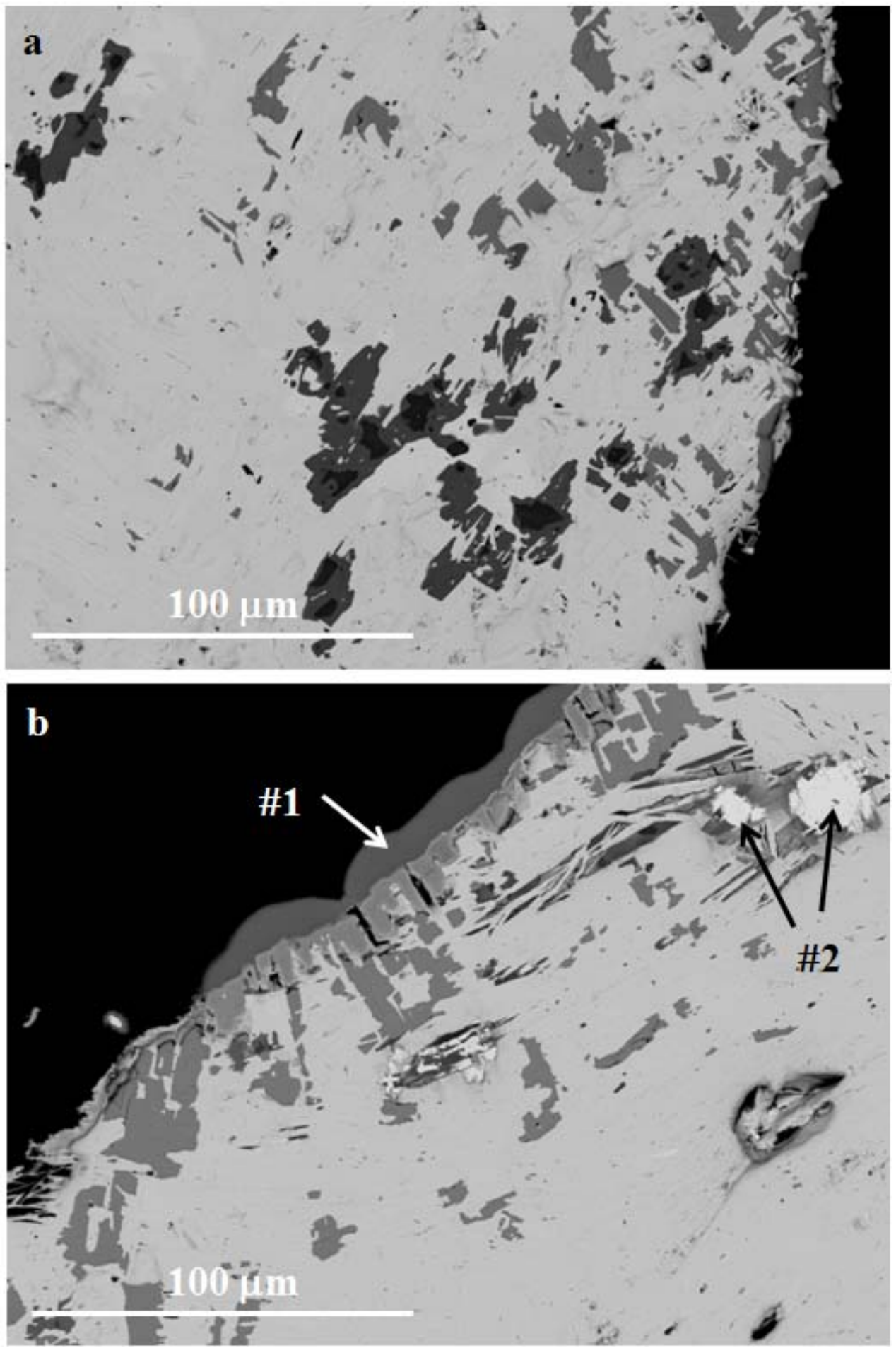
Figure 3
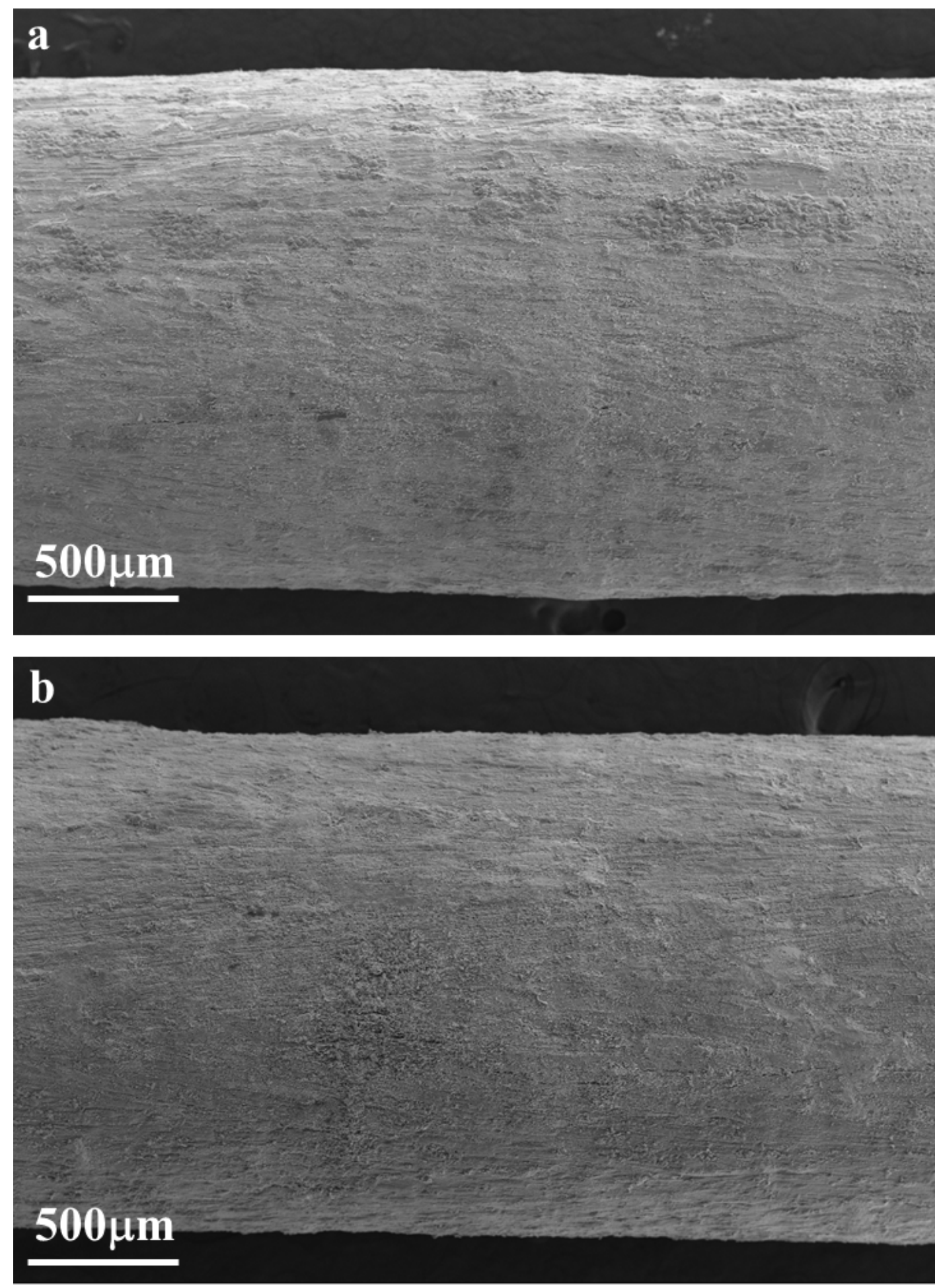
Figure 4
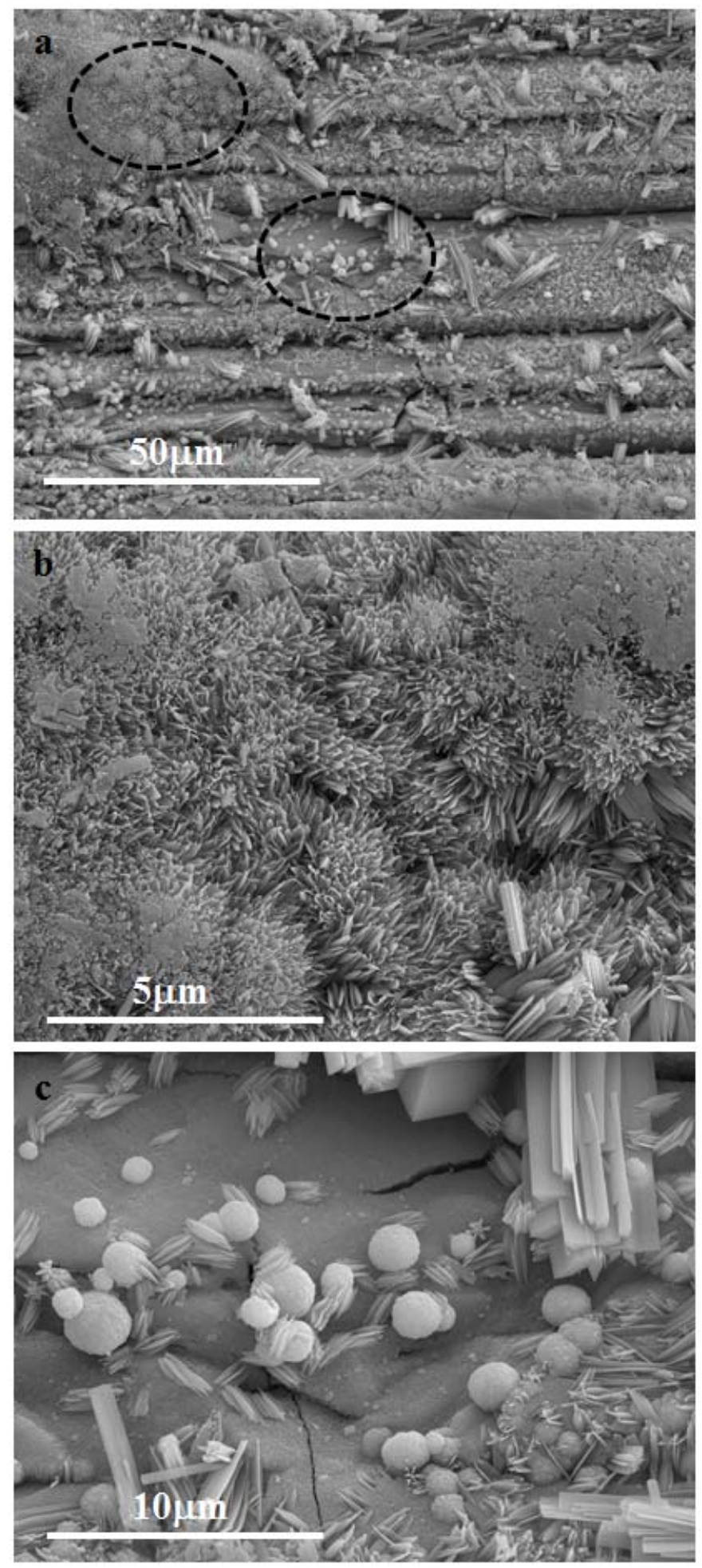
Figure 5

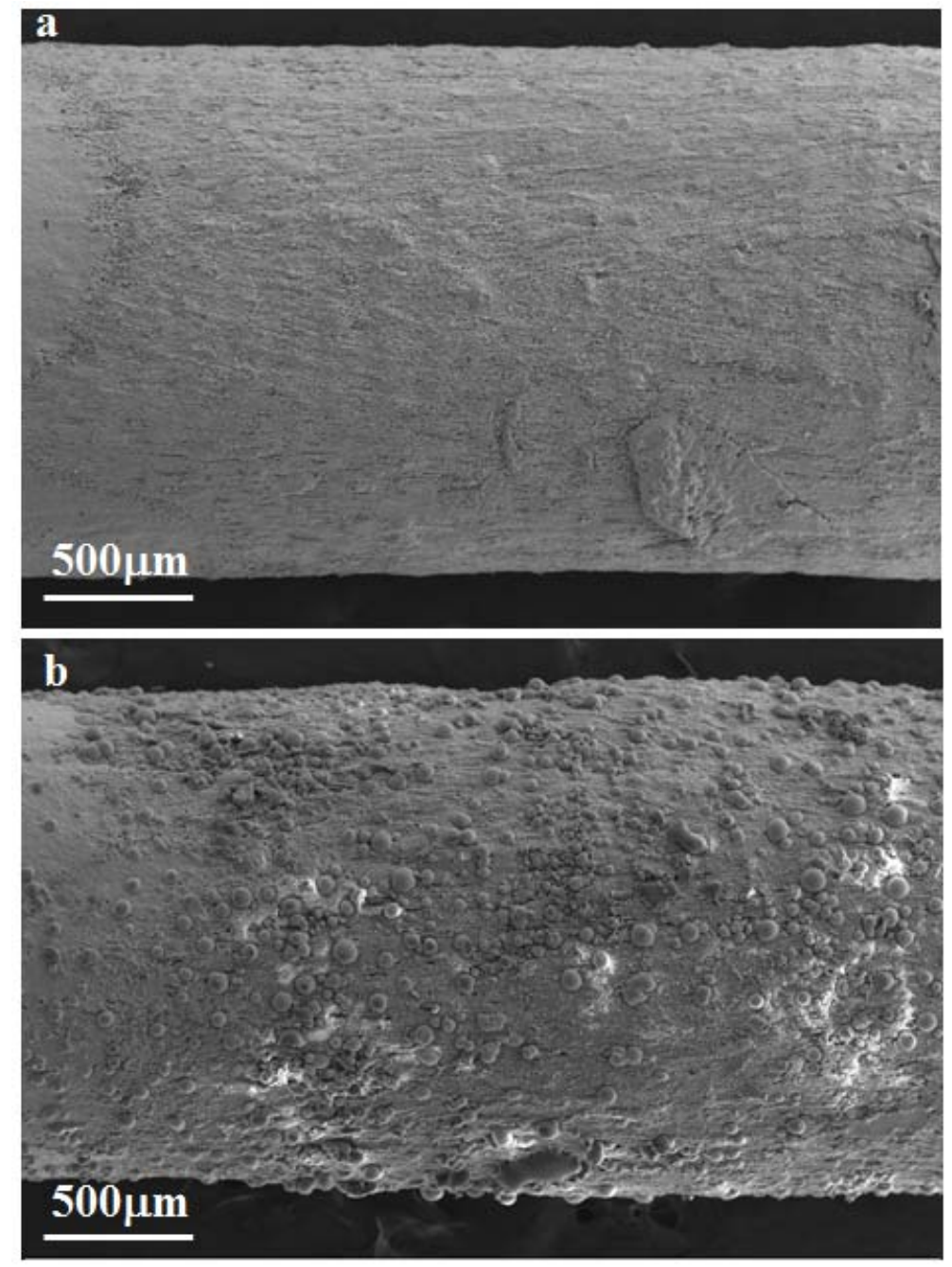


Figure 6

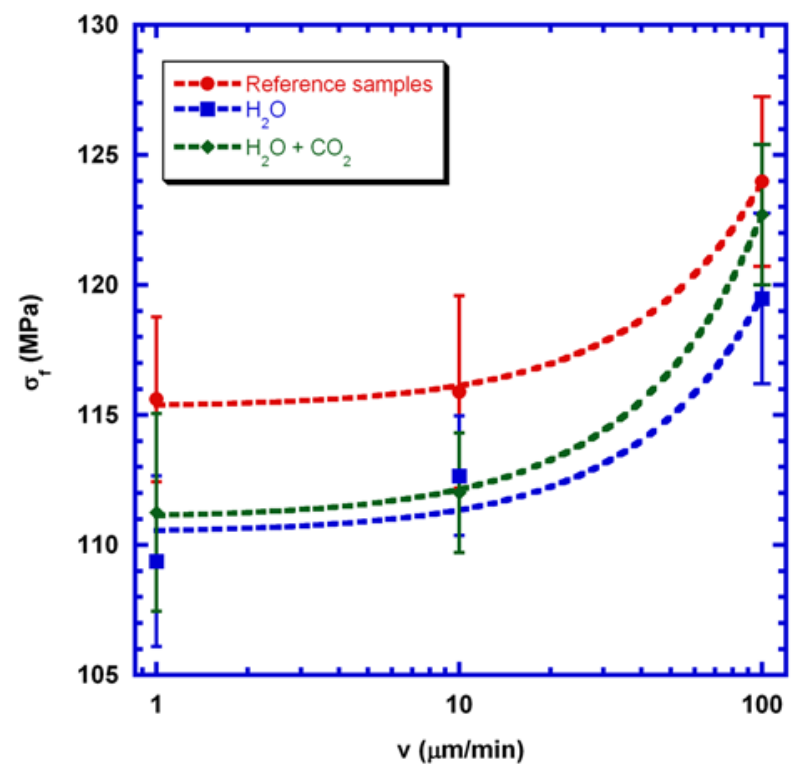


Figure 7

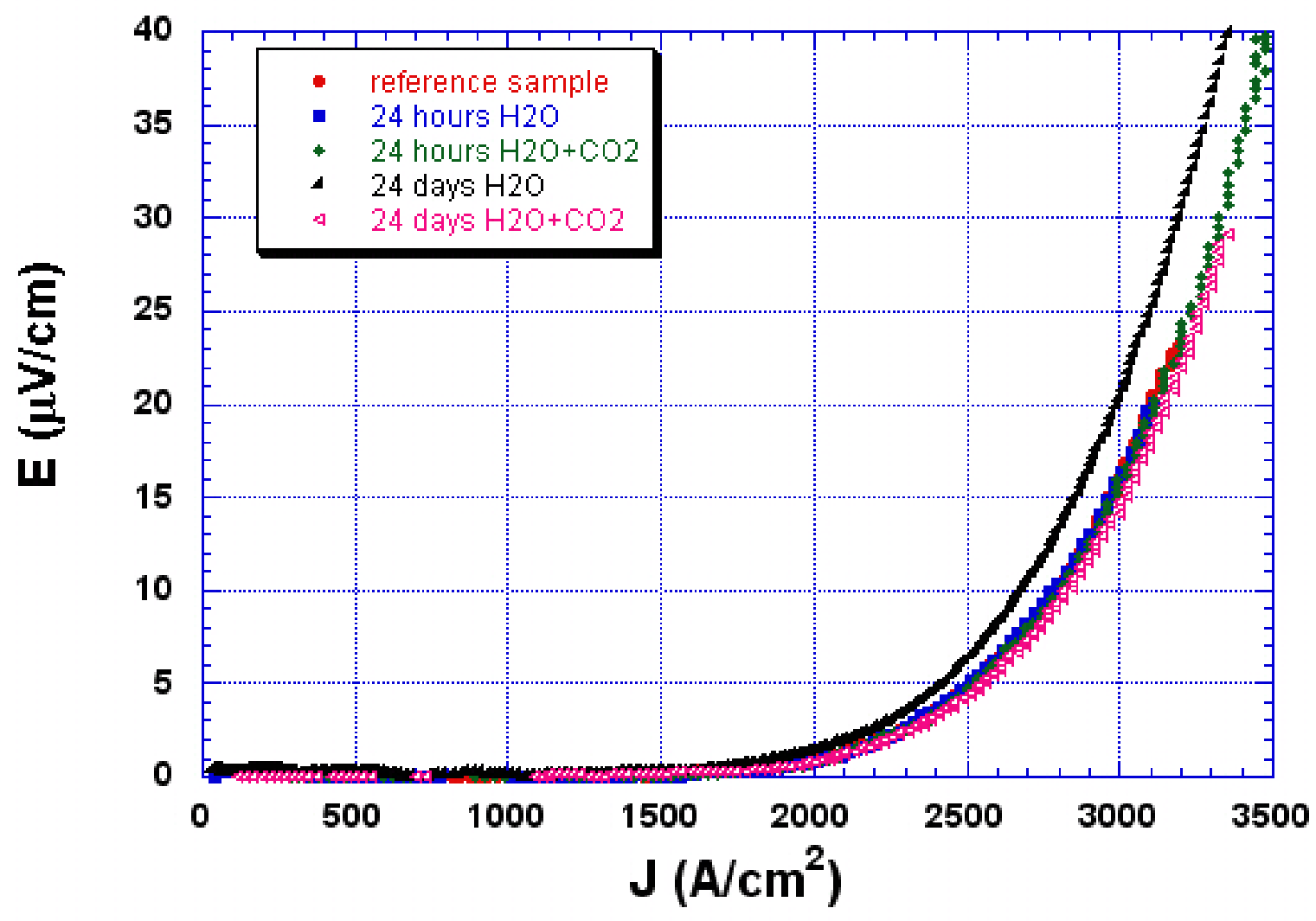

